\title{
Change in the biomechanical characteristics of running as a result of an individual 1-year program for training an elite athlete with visual impairment for Paralympic Games
}

\author{
DOI: https://doi.org/10.5114/pq.2020.95771
}

\author{
Zhanneta Kozina', Olena Chaika², Ivan Prokopenko ${ }^{3}$, Vadym Zdanyuk ${ }^{4}$, Hanna Kniaz ${ }^{5}$, Olexsii Proskurnia ${ }^{6}$, \\ Andrii Chernozub ${ }^{7}$, Yurii Shkrebtii ${ }^{8}$, Yana Romantsova ${ }^{9}$ \\ ${ }^{1}$ Department of Olympic and Professional Sport and Sport Games, H.S. Skovoroda Kharkiv National Pedagogical \\ University, Kharkiv, Ukraine \\ ${ }^{2}$ Department of Physical Culture, Ivan Kozhedub Kharkiv National University of Air Force, Kharkiv, Ukraine \\ ${ }^{3}$ H.S. Skovoroda Kharkiv National Pedagogical University, Kharkiv, Ukraine \\ ${ }^{4}$ Department of Physical Rehabilitation and Medical and Biological Bases of Physical Education, Kamianets-Podilskyi \\ Ivan Ohiienko National University, Kamianets-Podilskyi, Ukraine \\ ${ }^{5}$ Department of Practice of English Oral and Written Speech, H.S. Skovoroda Kharkiv National Pedagogical University, \\ Kharkiv, Ukraine \\ ${ }^{6}$ Department of Mathematics, H.S. Skovoroda Kharkiv National Pedagogical University, Kharkiv, Ukraine \\ 7 Department of Medical and Biological Foundations of Sport and Physical Rehabilitation, Black Sea National University \\ named after Petro Mohyla, Mykolayiv, Ukraine \\ ${ }^{8}$ Department of Water Sports, National University of Ukraine on Physical Education and Sport, Kiev, Ukraine \\ ${ }^{9}$ Department of Foreign Languages No. 1, Yaroslav Mudryi National Law University, Kharkiv, Ukraine
}

\section{Abstract}

Introduction. To identify the effectiveness of an individual track and field sprint training program for an elite athlete with visual impairment to improve running techniques and increase competitive performance.

Methods. An elite athlete, a Paralympic medallist and winner in the 2016 World Championship of Athletes with Disabilities was involved in the study. An individual training program was developed, based on improving speed endurance and the kinaesthetic analyser. The biomechanical indicators of running were determined for $100-\mathrm{m}$ running.

Results. The value of the angle in the knee joint at the time of thigh raising, as well as the speed of movement of the ankle and knee joints at the time of thigh raising and at the time of lowering the leg increased significantly $(p<0.05)$. A significant decrease in the running time of running steps during the development of maximum speed at a distance $(p<0.05)$ was revealed. Elimination of delays in lowering the leg after thigh raising was found. The time of $100-\mathrm{m}$ running decreased significantly.

Conclusions. The athlete became the champion of the world and the silver medallist of the Paralympics in 2016 as a result of applying the individually developed training program.

Key words: sprint, visual impairment, running, biomechanical indicators, Paralympic Games

\section{Introduction}

Individualization of the training process is relevant at all stages of the formation of athletes [1, 2], since the success of each athlete is ensured by a unique combination of various aspects that determine the sporting result [3-5]. An individual approach requires special attention at the stage of high sports achievements [6, 7]. In this period, along with the traditionally known factors of sports training, the nuances of technique, psychophysiological indicators, the quality of the body recovery after training $[7,8]$, the patterns of fluctuations in the functional state, and the like are becoming especially important for each athlete $[9,10]$. These provisions apply to all sports, but in athletics individualization is of particular importance, since the discipline requires the maximum manifestation of physical qualities [11-13].

For representatives of Paralympic sports, individualization of training becomes an essential aspect as individual characteristics associated with impaired functions are added to the individual characteristics of healthy athletes [14, 15]. One of the observed dysfunctions is that of the visual analyser. Therefore, Paralympic athletes who perform in various competitive categories for participants with visual impairment are forced not only to overcome the difficulties of training and competitive activity common to all athletes [15, 16]. They also have to face the complexity of perceiving information since a healthy person perceives $80-90 \%$ of the information of the surrounding world through the visual analyser [16]. Therefore, in the preparation of Paralympic competitors with visual impairment, not only training factors characteristic of all athletes, but also the development of compensatory mechanisms are of particular importance [14-16].

It should be noted that in Paralympic athletics sprint, each athlete presents a unique combination of individual characteristics with regard to the development of physical qualities, biomechanics of running, neurodynamic and psychophysiological indicators, and features of physical disorders. From this point of view, the study of an elite athlete as a separate

Correspondence address: Zhanneta Kozina, Department of Olympic and Professional Sport and Sport Games, H.S. Skovoroda Kharkiv National Pedagogical University, Altshevskih Str. 29, Kharkiv, 61002, Ukraine, e-mail: zhanneta.kozina@gmail.com 
single case is of great importance for understanding the principles of compiling and adjusting individual programs on the basis of the identification of the strengths and weaknesses of the athlete. This can be a valuable experience in terms of determining mechanisms to compensate for the lack of visual function and finding ways to improve athletic performance of Paralympic sprint runners. In this context, studies conducted in individual athletes as unique representatives of the interaction of various factors that determine the achievement of sports results are of great importance.

In our previous research $[5,15,16]$, we implied that studies performed with the participation of an elite Paralympic sprint runner with visual impairment are important not only for conclusions regarding the preparation of the particular athlete but also with reference to identifying an individual approach algorithm in training elite athletes with visual impairment. In our previous studies, on the basis of the developed algorithm for determining individual characteristics $[5,6,15]$, data were obtained that allowed to specify neurodynamic factors of maintaining a high speed at a distance for an athlete with visual impairment. So, it was revealed that the examined athlete was an atypical sprinter in terms of the properties of the nervous system, the development and maintenance of speed at a distance, and some biomechanical characteristics of running. It was found that the speed achieved by the competitor at a distance was slightly higher than that of other athletes of similar qualifications. However, the time to obtain and the time to maintain maximum speed was longer compared with other athletes of the same qualification. It was also shown that the investigated athlete had a mobile and strong type of the nervous system [16]. This helped her maintain a higher speed at a distance for a longer time compared with other athletes, which can be considered as a potential reserve $[3,4,8]$. There was also a slight unevenness in the change in speed and acceleration of the movement of the ankle and knee joints observed in some steps when lowering the limb after the hip was raised [17]. On the basis of a correlation analysis of neurodynamic and biomechanical characteristics, we pointed at an average and high significant relationship between the performance of the nervous system and running biomechanics [17]. We concluded that the need to improve the biomechanics of running by focusing on the work of the kinaesthetic analyser could result in an increase in speed at a distance with its preservation almost to the finish line [17].

In this context, a hypothesis was put forward here that an individually constructed training program based on the biomechanical characteristics of running and the neurodynamic functions would efficiently improve the competitive result of an elite athlete with visual impairment.

The purpose of the work was to identify the effectiveness of an individual track and field sprint training program for an elite athlete with visual impairment to improve running techniques and increase competitive performance.

\section{Subjects and methods}

\section{Participant}

The study involved a highly skilled female athlete specializing in short distances and long jump, the 2010 European Athletics Champion, the winner of the 2016 Paralympic Games and the World Championship of Athletes with Disabilities (category T12). T12 is a category of visually impaired competitors. All athletes with disabilities are classified for the degree of visual impairment.
The examined athlete performs in the T12 category owing to myopia in combination with retinal dystrophy. However, she can work on a computer at a distance of $30-50 \mathrm{~cm}$.

\section{Determining biomechanical indicators of running in the elite athlete with visual impairment}

The biomechanical indicators of running were established by analysing video tracks of the runs by using the Kinovea software, version 0.8.15 [18]. Kinovea allows to perform video analysis of movements. It is intended for athletes, coaches, health workers, researchers in the field of sport. Also, the software can be useful for experts in ergonomics or animation. The main function of Kinovea is to display and analyse sports videos. The main tools include 'Line,' 'Chronometer,' 'Tracking'. The 'Line' and 'Chronometer' functions allow to measure distance and time, and with the 'Semi-automatic tracking' tool, one can track both the trajectory and time. When working with Kinovea, the user can watch videos from external sources: video cameras, smartphones, etc. It is enough to save the video files on a computer and then load them into the program and conduct a video analysis; the software recognizes the files independently.

For the analysis of biomechanical parameters, 2 running steps of the athlete were selected at the moment of reaching the maximum running speed per $100 \mathrm{~m}$ (17 frames) (Figure 1). Distance calibration was carried out with the length of the athletics barrier $(92.3 \mathrm{~cm})$. The travel time was determined by stopwatch indicators in the software. We also established the speed of movement of the ankle joint $\left(\mathrm{m} \cdot \mathrm{s}^{-1}\right)$ (Figure 2), the speed of movement of the knee joint $\left(\mathrm{m} \cdot \mathrm{s}^{-1}\right)$, and the angle at the knee joint (degrees) (Figure 3). The acceleration of the movement of these points was automatically determined $\left(\mathrm{m} \cdot \mathrm{s}^{-2}\right)$. The force developed by the extremity $(\mathrm{N})$ was implied by the formula:

$$
\mathrm{F}=\mathrm{ma}
$$

where: $\mathrm{F}$ - force developed by the limb, $\mathrm{m}$ - the mass of a limb (approximately $13 \mathrm{~kg}$ ), a - acceleration of the movement of the knee joint.

In total, 36 videos of $100-m$ running were analysed; in each video, 17 frames (2 running steps) with the athlete reaching the maximum running speed were selected for analysis.

In addition, points were determined by time and distance to reach the maximum speed at the distance of $100 \mathrm{~m}$; here, 36 videos were also analysed. The obtained data regarding the moment of reaching the maximum speed at a distance and the beginning of its decrease were compared with literature data.

\section{Course of study}

Initially, the individual biomechanical running characteristics and running results of $60 \mathrm{~m}, 80 \mathrm{~m}, 100 \mathrm{~m}, 120 \mathrm{~m}, 150$ $\mathrm{m}$, and $200 \mathrm{~m}$ were analysed during May-June 2015 (end of the precompetitive period of the 2015 annual cycle). The running results were recorded in training sessions as well as in formal and informal competitions. In total, 36 results were analysed.

To detect the impact of the developed 2016 Paralympics training program, running results of $60 \mathrm{~m}, 80 \mathrm{~m}, 100 \mathrm{~m}, 120 \mathrm{~m}$, $150 \mathrm{~m}$, and $200 \mathrm{~m}$ and biomechanical parameters during May-June 2016 (end of pre-season annual cycle; preparation for the 2016 Paralympics) were also recorded. 

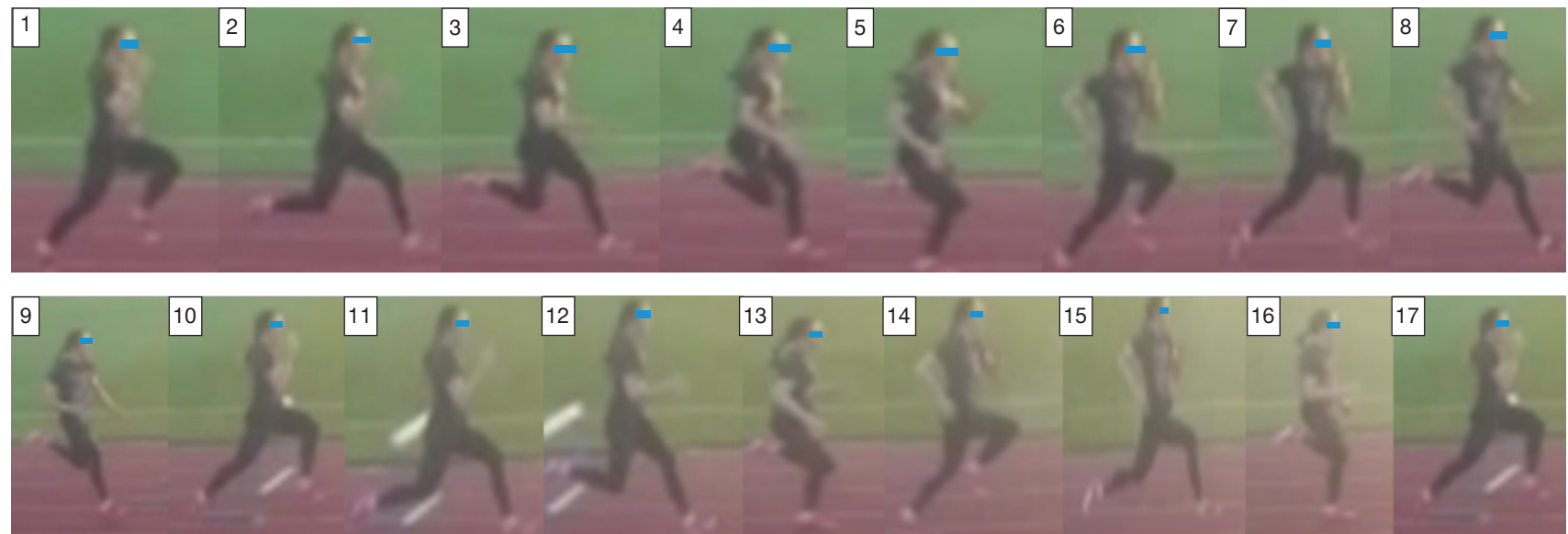

Figure 1. An example of a videogram of a 100-m running of an elite sportswoman with visual impairment (author's photographs)
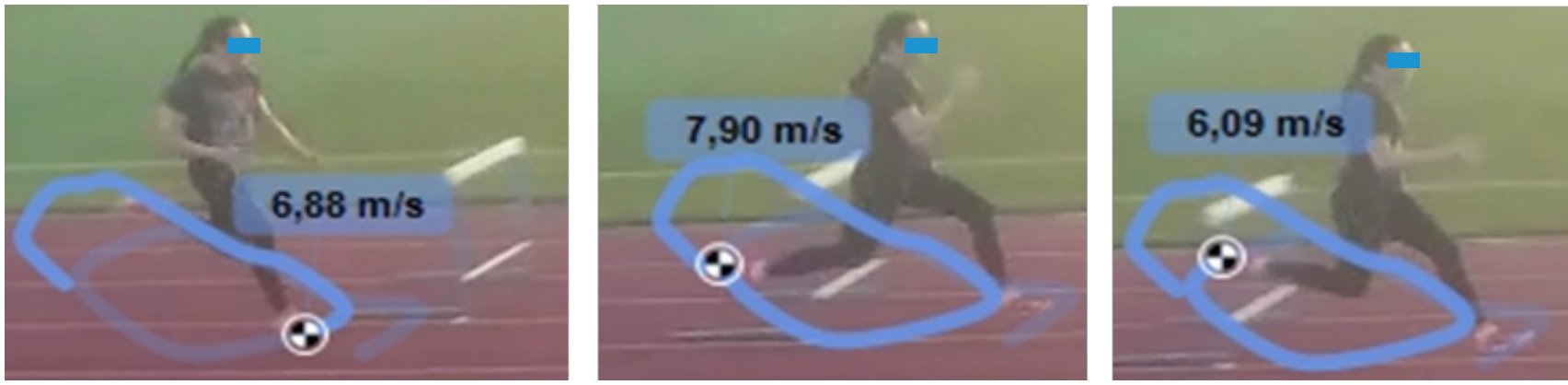

Figure 2. An example of automatic determination of the speed of a point in space (ankle) along a curved path by using the Kinovea software (author's photographs)
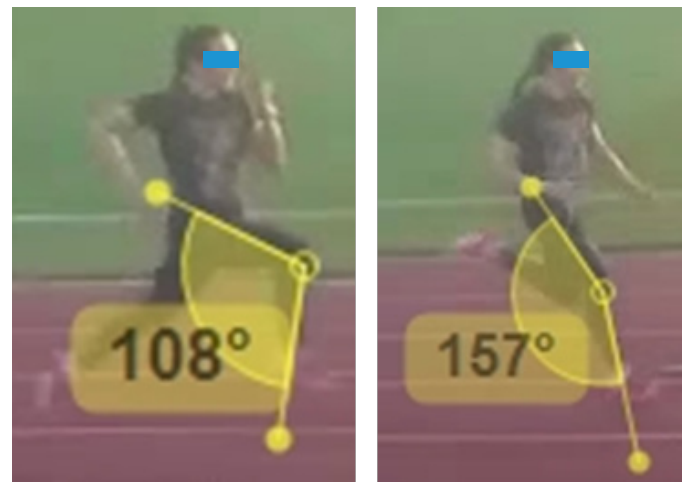

Figure 3. An example of automatic determination of the angle in the knee joint by using the Kinovea software (author's photographs)

General principles of building the training process of the elite athlete in the annual cycle

Complex methods of individualization were implemented in the system of training of the elite sportswoman with impaired vision, with the consideration of the peculiarities of the individual readiness structure. The system of means and methods for the training process individualization assumed the following provisions.

In the development of the individual training program, emphasis was put on the leading factors in the athlete's individual readiness structure, her tendency to a certain style of motor activity. Factors that amounted to more than $50 \%$ in the individual readiness structure were designated as leading, other factors lagging behind. In accordance with the existing models of interconnection in different preparedness factors development, $60-80 \%$ of individual training was allocated for the development of leading factors, and $20-40 \%$ for the development of lagging factors.

The emphasis on the development of leading factors increased as the competition approached [2, 14]. In the competitive period, the ratio of funds aimed at the development of leading and lagging factors was 70:30.

In drawing up the training program, the individual wavypatterned regularities of the 'ups and downs' of the sports form were taken into account $[2,6]$. During the periods of 'lifting,' the athlete performed more exercise. During the periods of 'recessions,' there was an increase in the use of means of restoring work capacity and decreased load, as well as in the relative volume of funds aimed at the development of leading factors of individual readiness, up to 75-80\%; also, technology was more widely used.

On the basis of the peculiarities of the individual factor structure of preparedness and patterns of dynamics of the 


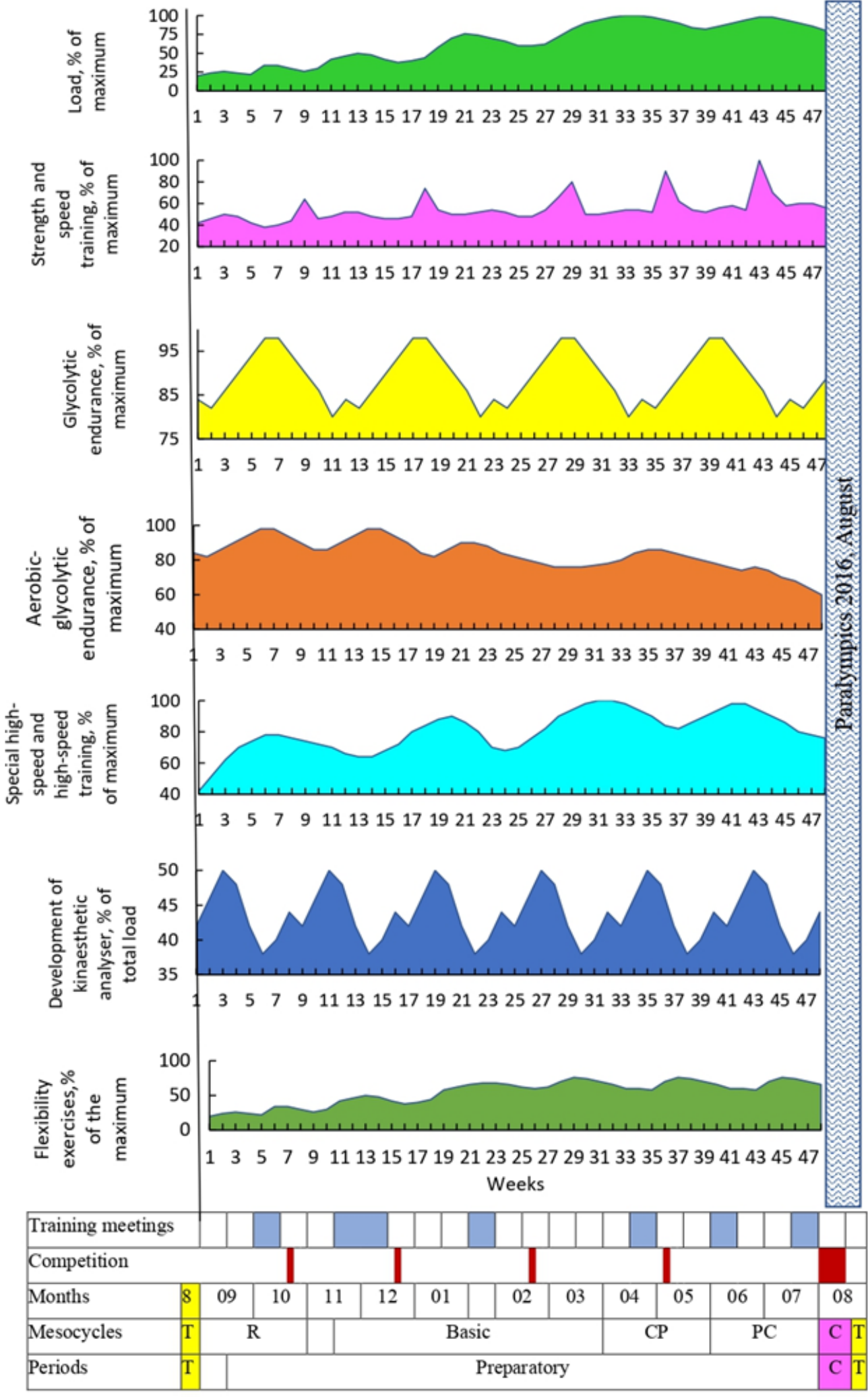

$\mathrm{T}$ - transition period (mesocycle) $\mathrm{R}$ - retractable mesocycle $\mathrm{CP}$ - control-preparatory mesocycle $\mathrm{PC}$ - precompetitive mesocycle C - competitive period (mesocycle)
Figure 4. The construction of the annual cycle of training for the elite sportswoman with impaired vision functional state, we implemented methods to apply means of psychophysical training, to develop the ability to maintain balance, and to improve special physical qualities. The factors in the individual structure of the athlete's preparedness with correlating indicators were identified and the distribution of the means of physical, technical, psychophysical, and psychological training in the individual training program was compiled. Models of distribution of funds by types of training depending on the periods of sports form dynamics were drawn up. The percentage of funds in the training program varied, subject to the leading factor in the structure of preparedness and the period of the functional state dynamics (Figure 4).

The establishment and implementation of the annual training system was subordinated to the main task - to reach the peak of readiness during the main competitions of the year: World Championships and Paralympic Games 2016. For this purpose, the maximum permissible volumes and intensity of training and competitive activities during the year and the Paralympics were carried out. 
The periodization and content of the training during the pre-Olympic year were built on a 1-cycle basis. The total number of training hours per year was 1400 . The structure of the annual training cycle included 3 periods:

- preparatory: September 2015 - July 2016; 1270 hours, $90.7 \%$ of the total number of hours in the annual cycle;

- competitive: August, first half; 70 hours, $5 \%$ of the total number of hours in the annual cycle;

- transitional: August, second half; 60 hours, $4.3 \%$ of the total number of hours in the annual cycle.

In the structure of the preparatory period, there were 4 mesocycles:

- retractable: September-October 2015, 240 hours;

- basic: November 2015 - March 2016, 610 hours;

- control-preparatory: April-May 2016, 210 hours;

- precompetitive: June-July 2016, 210 hours.

The competitive period included 1 mesocycle - directly participating in the 2016 Paralympic Games, the first half of August 2016, including the flight adaptation period.

The transitional period denoted the time after the Paralympics, until the start of the next annual cycle.

The basic means, methods, and conditions of preparing the elite athlete with impaired vision for the 2016 Paralympics included the use of physical and ideomotor exercises and autogenic training [19].

\section{Unstable supports for kinaesthetic analyser development}

In the training process of the elite athlete with impaired vision, we decided to include exercise with unstable platforms as a means to develop compensatory mechanisms for visual analyser function failure. This was based on literature reports describing benefits of training on unstable platforms for the development of kinaesthetic analyser [20-22]. The following exercises were applied on an unstable support (pillow): imitation of carrying out of a leg for a running step; simulation of running a running step (Figure 5); a stand on one leg with the other leg diverted back; squat and half-squat on one leg; half-squat on one leg with the other leg diverted back and aside; flamingo balance exercise; and others.

The exercises on unstable support were applied at the beginning of training, after warm-up. The total duration of the equilibrium exercises was 15-20 minutes. These were also applied at home daily in the morning, with the total duration of 15 minutes.

\section{Statistical analysis}

The digital material obtained during the study was processed with traditional methods of mathematical statistics. For each indicator, the arithmetic mean, root mean square deviation (standard deviation), and standard error were determined.

The data obtained by repeated testing of the athlete for biomechanical running characteristics and the results of shortdistance running in May-June 2015 (36 measurements of each indicator) were compared with those obtained in MayJune 2016 (36 measurements of each indicator). The accuracy of the differences was determined by Student's $t$-test. Differences and reliability of correlation coefficients were considered significant at the level of $p<0.05$. The mathematical processing of the data was performed with Microsoft Excel 2016 and SPSS-17 data analysis software.

\section{Ethical approval}

The research related to human use has complied with all the relevant national regulations and institutional policies, has followed the tenets of the Declaration of Helsinki, and has been approved by the authors' institutional review board or an equivalent committee.

\section{Informed consent}

Informed consent has been obtained from the individual included in this study.

\section{Results}

The biomechanical analysis of indices of motion of points on the ankle and knee joints, as well as the angle in the knee joint and the force developed in the lower extremity showed the effectiveness of the program for preparing the elite athlete with impaired vision to the Paralympics (Table 1, Figures 6-8).

The time of limb movements at the running steps decreased, which indicates an increase in speed (Table 1, Figures 6 and 7). There was a ignificant increase in the magnitude of the knee joint angle at the time of thigh raising (Table 1, Figure 8), the speed of ankle motion (Table 1, Figure 6), and the speed of knee joint motion (Table 1, Figure 7) at the time of thigh raising and the limb lowering.

It should also be noted that the changes in the speed of movement of the ankle and knee joints became somewhat

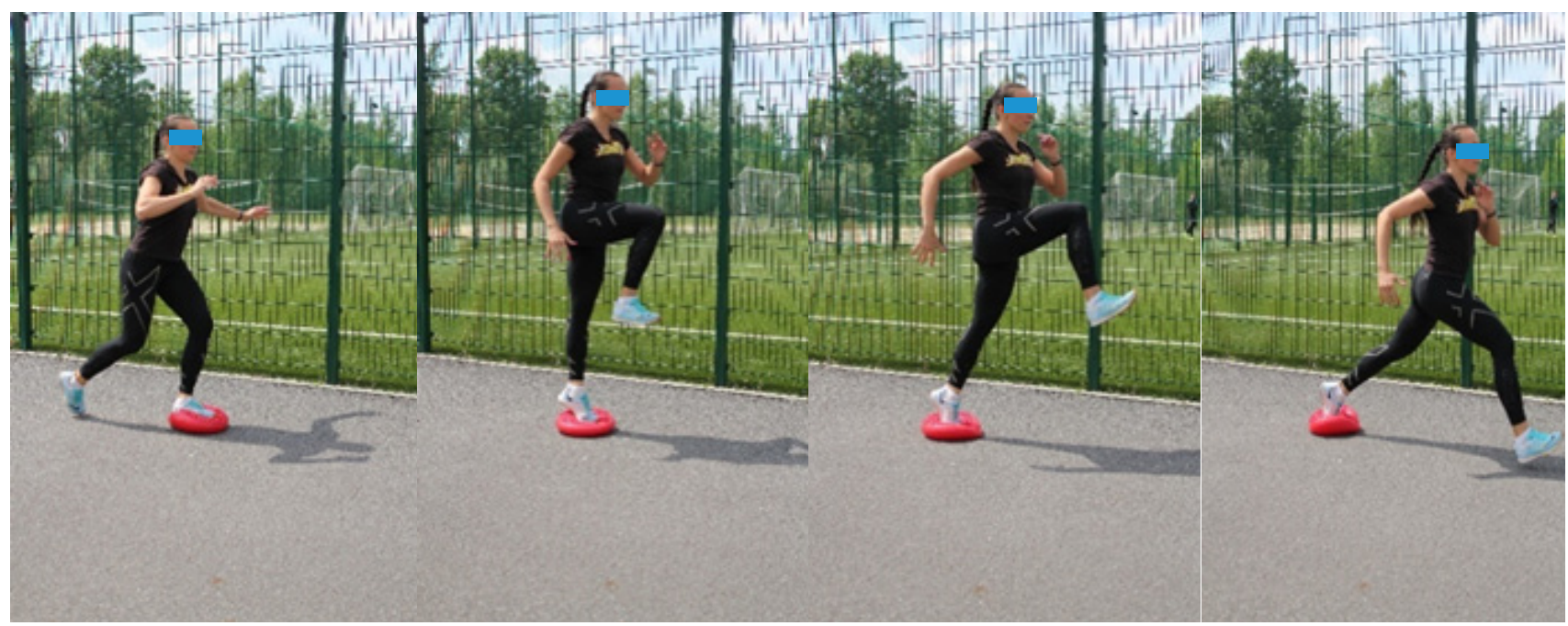

Figure 5. An example of an exercise on an unstable support: imitation of a running step (author's photographs) 
Table 1. Biomechanical characteristics of the elite athlete's 100-m running in May-June $2015(n=36)$ and May-June $2016(n=36)$

\begin{tabular}{|c|c|c|c|c|c|c|c|c|c|c|c|c|c|c|}
\hline \multirow{2}{*}{$\begin{array}{l}\text { Frame, } \\
\text { Figure } 4\end{array}$} & \multirow{2}{*}{$\begin{array}{c}\text { Testing } \\
\text { period, } \\
\text { year }\end{array}$} & \multirow[t]{2}{*}{$\mathrm{t}(\mathrm{ms})$} & \multicolumn{2}{|c|}{$\begin{array}{c}\text { Knee angle (left) } \\
\text { (degrees) }\end{array}$} & \multicolumn{2}{|c|}{$\begin{array}{l}\mathrm{v} \text {, ankle (right) } \\
\left(\mathrm{m} \cdot \mathrm{s}^{-1}\right)\end{array}$} & \multicolumn{2}{|c|}{$\begin{array}{c}\text { a, ankle (right) } \\
\left(\mathrm{m} \cdot \mathrm{s}^{-2}\right)\end{array}$} & \multicolumn{2}{|c|}{$\begin{array}{c}\mathrm{v}, \text { knee joint (left) } \\
\left(\mathrm{m} \cdot \mathrm{s}^{-1}\right)\end{array}$} & \multicolumn{2}{|c|}{$\begin{array}{c}\text { a, knee joint (left) } \\
\left(\mathrm{m} \cdot \mathrm{s}^{-2}\right)\end{array}$} & \multicolumn{2}{|c|}{$\mathrm{F}(\mathrm{N})$} \\
\hline & & & $\bar{x}$ & $S D$ & $\bar{x}$ & $S D$ & $\bar{x}$ & $S D$ & $\bar{x}$ & $S D$ & $\bar{x}$ & $S D$ & $\bar{x}$ & $S D$ \\
\hline \multirow{2}{*}{1} & 2015 & 5.00 & 143 & 4.32 & 2.94 & 0.23 & 58.80 & 3.71 & 1.16 & 0.11 & 23.20 & 1.62 & 301.6 & 7.13 \\
\hline & 2016 & 5.00 & 145 & 3.49 & $3.06^{*}$ & 0.18 & 61.2 & 3.24 & 1.26 & 0.08 & 25.2 & 1.54 & 327.6 & 6.87 \\
\hline \multirow{2}{*}{2} & 2015 & 10.00 & 133 & 3.22 & 2.81 & 0.15 & 56.20 & 3.83 & 0.88 & 0.06 & 17.60 & 1.23 & 228.8 & 21.11 \\
\hline & 2016 & 9.00 & 133 & 3.12 & 2.82 & 0.12 & $70.5^{\star \star \star}$ & 2.45 & 0.98 & 0.04 & 24.5 & 1.11 & 318.5 & 20.19 \\
\hline \multirow{2}{*}{3} & 2015 & 12.00 & 115 & 2.12 & 4.79 & 0.89 & 159.67 & 9.65 & 3.32 & 0.45 & 110.67 & 7.75 & 1438.71 & 16.02 \\
\hline & 2016 & 11.00 & 115 & 2.01 & $5.15^{\star}$ & 0.76 & $257.5^{\star \star \star}$ & 9.65 & $3.78^{\star *}$ & 0.36 & 189.0 & 7.43 & 2457.0 & 15.78 \\
\hline & 2015 & 15.00 & 56 & 1.23 & 3.04 & 0.78 & 101.33 & 7.36 & 2.76 & 0.36 & 92.00 & 6.44 & 1196 & 100.71 \\
\hline & 2016 & 14.00 & 56 & 0.76 & 3.10 & 0.65 & 103.3 & 7.23 & 2.89 & 0.25 & 96.3 & 5.46 & 1252.2 & 98.34 \\
\hline & 2015 & 19.00 & 28 & 1.01 & 2.98 & 0.56 & 74.50 & 5.64 & 1.46 & 0.12 & 36.50 & 2.56 & 474.5 & 83.72 \\
\hline & 2016 & 18.00 & 28 & 0.87 & 3.02 & 0.34 & 75.5 & 5.21 & $1.68^{*}$ & 0.08 & $42.0^{\star *}$ & 2.13 & $546.0^{\star \star \star}$ & 67.16 \\
\hline \multirow{2}{*}{0} & 2015 & 27.00 & 31 & 1.34 & 10.97 & 1.34 & 137.13 & 9.13 & 7.14 & 0.28 & 89.25 & 6.25 & 1160.25 & 33.22 \\
\hline & 2016 & 24.00 & 31 & 0.98 & $11.58^{*}$ & 1.27 & $193.0^{* *}$ & 8.97 & $8.14^{\star \star}$ & 0.19 & $135.6^{* \star *}$ & 5.79 & $1763.7^{\star \star *}$ & 31.12 \\
\hline \multirow{2}{*}{7} & 2015 & 30.00 & 61 & 1.89 & 4.70 & 0.67 & 156.67 & 11.3 & 1.77 & 0.11 & 59.00 & 4.13 & 767 & 81.22 \\
\hline & 2016 & 27.00 & 61 & 0.87 & $10.82^{\star \star \star}$ & 0.58 & $320.6^{\star \star *}$ & 10.2 & $8.19^{\star \star \star}$ & 0.08 & 233.0 & 3.89 & $3029.0^{\star * *}$ & 76.39 \\
\hline \multirow{2}{*}{8} & 2015 & 35.00 & 108 & 2.21 & 6.32 & 0.69 & 126.40 & 8.63 & 3.49 & 0.43 & 69.80 & 4.89 & 907.4 & 53.69 \\
\hline & 2016 & 33.00 & $119^{*}$ & 1.25 & 6.53 & 0.57 & 108.8 & 8.54 & $4.79^{\star *}$ & 0.34 & $79.8^{* *}$ & 4.56 & $1037.7^{\star * *}$ & 45.32 \\
\hline \multirow{2}{*}{ g } & 2015 & 41.00 & 134 & 3.23 & 4.05 & 0.34 & 67.50 & 6.43 & 0.58 & 0.08 & 9.67 & 0.68 & 125.71 & 63.52 \\
\hline & 2016 & 38.00 & $142^{*}$ & 3.11 & 4.18 & 0.29 & $83.6^{\star \star}$ & 6.12 & $0.78^{\star *}$ & 0.06 & $15.6^{\star *}$ & 0.53 & 202.8 & 51.84 \\
\hline \multirow{2}{*}{10} & 2015 & 45.00 & 157 & 4.55 & 9.68 & 0.78 & 242.00 & 19.3 & 3.80 & 0.34 & 95.00 & 6.65 & 1235 & 8.80 \\
\hline & 2016 & 42.00 & $162^{*}$ & 3.89 & $10.06^{*}$ & 0.76 & $251.5^{\star}$ & 18.2 & $4.99^{\star *}$ & 0.25 & $184.75^{\star \star}$ & 5.21 & $2401.7^{\star \star \star}$ & 7.41 \\
\hline \multirow{2}{*}{11} & 2015 & 51.00 & 143 & 3.21 & 7.05 & 0.65 & 117.50 & 10.5 & 2.35 & 0.12 & 39.17 & 2.74 & 509.21 & 86.45 \\
\hline & 2016 & 49.00 & 149 & 2.78 & 7.76 & 0.56 & $290.8^{\star \star \star}$ & 9.98 & $2.57^{* *}$ & 0.09 & $86.7^{\star *}$ & 2.36 & $1127.2^{\star \star \star}$ & 76.45 \\
\hline \multirow{2}{*}{12} & 2015 & 55.00 & 138 & 2.89 & 4.65 & 0.38 & 116.25 & 10.1 & 1.57 & 0.07 & 39.25 & 2.75 & 510.25 & 35.64 \\
\hline & 2016 & 52.00 & 141 & 2.76 & 4.82 & 0.26 & 160.6 & 9.14 & $1.77^{\star}$ & 0.03 & $59.0^{* *}$ & 2.31 & $767.0^{\star * \star}$ & 34.57 \\
\hline \multirow{2}{*}{13} & 2015 & 60.00 & 128 & 2.45 & 3.58 & 0.21 & 71.60 & 6.32 & 1.20 & 0.06 & 24.00 & 1.68 & 312 & 35.72 \\
\hline & 2016 & 58.00 & 131 & 2.32 & 3.86 & 0.18 & 64.3 & 6.23 & 1.45 & 0.02 & 24.17 & 1.54 & 314.21 & 32.45 \\
\hline \multirow{2}{*}{14} & 2015 & 65.00 & 93 & 1.98 & 8.22 & 0.28 & 164.40 & 14.4 & 5.09 & 0.17 & 101.80 & 7.13 & 1323.4 & 21.84 \\
\hline & 2016 & 62.00 & 93 & 1.23 & $8.94^{*}$ & 0.04 & $313.5^{\star \star \star}$ & 13.2 & $5.68^{*}$ & 0.11 & $232.0^{* *}$ & 6.14 & $3016.0^{* \star *}$ & 20.46 \\
\hline \multirow{2}{*}{15} & 2015 & 74.00 & 31 & 0.54 & 11.99 & 1.14 & 133.22 & 8.65 & 7.84 & 0.48 & 87.11 & 6.10 & 1132.43 & 92.64 \\
\hline & 2016 & 71.00 & 31 & 0.34 & $12.88^{*}$ & 0.02 & 143.1 & 7.56 & $8.56^{\star *}$ & 0.32 & $95.11^{* *}$ & 5.78 & 1236.4 & 88.65 \\
\hline & 2015 & 79.00 & 70 & 1.07 & 7.53 & 0.57 & 150.60 & 8.67 & 1.16 & 0.15 & 23.20 & 1.62 & 301.6 & 79.27 \\
\hline & 2016 & 76.00 & 70 & 0.87 & $7.71^{*}$ & 0.53 & 154.2 & 7.65 & $1.45^{\star}$ & 0.09 & 29.0 & 1.48 & 377.0 & 75.47 \\
\hline & 2015 & 84.00 & 117 & 2.45 & 8.62 & 0.62 & 172.40 & 11.5 & 5.09 & 0.47 & 101.80 & 7.13 & 1323.4 & 21.11 \\
\hline & 2016 & 81.00 & 117 & 2.43 & $9.06^{*}$ & 0.54 & $302.0^{* *}$ & 10.4 & $5.99^{\star *}$ & 0.34 & $199.67^{* \star} \mid$ & 6.58 & $2595.7^{* \star *}$ & 18.64 \\
\hline
\end{tabular}

$\mathrm{t}(\mathrm{ms})$ - time from the beginning of the first analysed step, $\mathrm{V}\left(\mathrm{m} \cdot \mathrm{s}^{-1}\right)$ - velocity of movement of a point in space,

a $\left(\mathrm{m} \cdot \mathrm{s}^{-2}\right)$ - acceleration of point motion in space $\left(\mathrm{m} \cdot \mathrm{s}^{-2}\right), \mathrm{F}(\mathrm{N})$ - force developed by the limb

* significant difference at $p<0.05$

** significant difference at $p<0.01$

*** significant difference at $p<0.001$ 


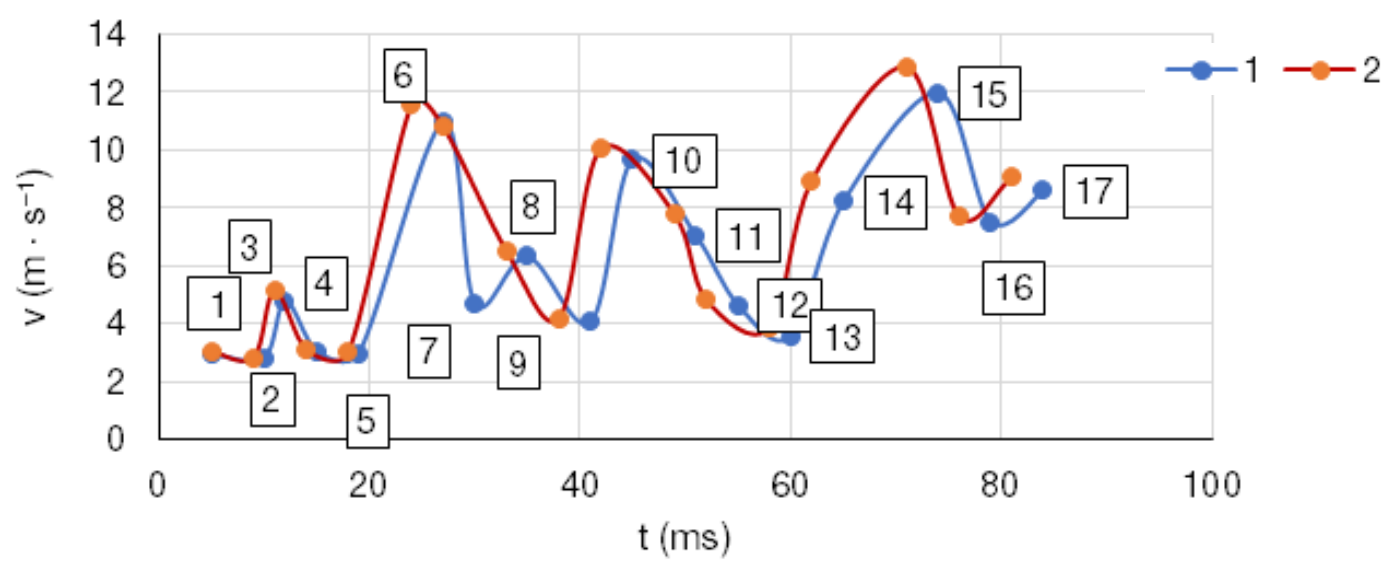

$\mathrm{v}\left(\mathrm{m} \cdot \mathrm{s}^{-1}\right)$ - speed of movement of the limb point, $\mathrm{t}(\mathrm{ms})$ - time from the beginning of the first analysed step, 1 - May-June 2015 ( $n=36), 2$ - May-June $2016(n=36)$, squares include numbers of the analysed points

Figure 6. Speed of ankle movement in the 100-m running of the elite athlete with impaired vision

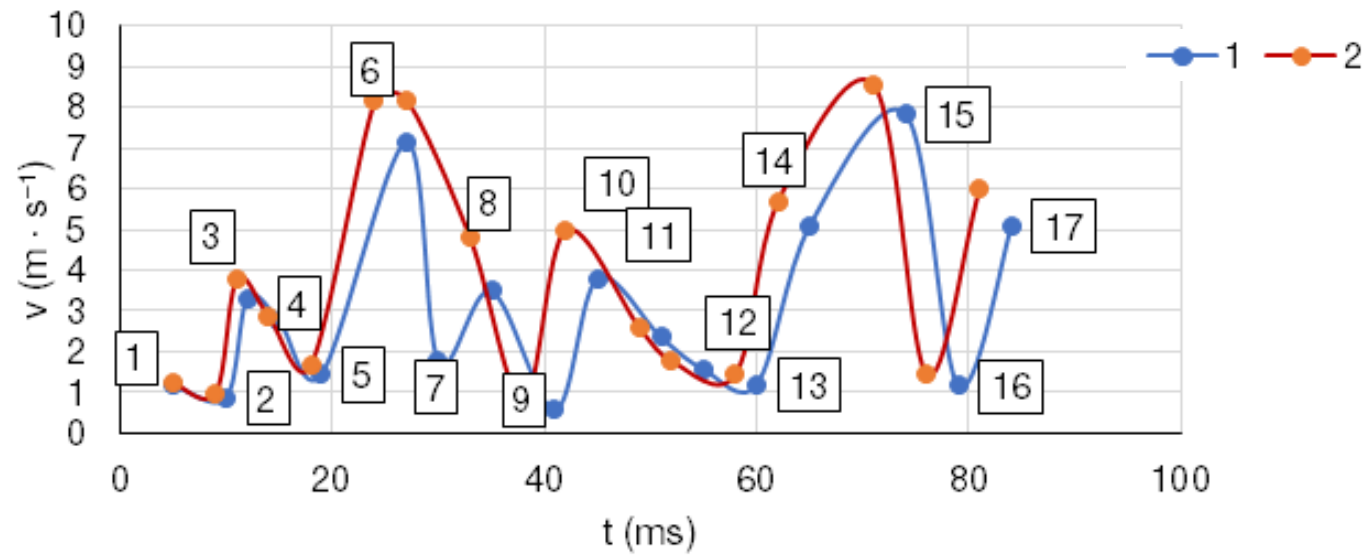

$\mathrm{v}\left(\mathrm{m} \cdot \mathrm{s}^{-1}\right)$ - speed of movement of the limb point, $\mathrm{t}(\mathrm{ms})$ - time from the beginning of the first analysed step,

1 - May-June $2015(n=36), 2$ - May-June $2016(n=36)$, squares include numbers of the analysed points

Figure 7. Speed of knee joint movement in the 100-m running of the elite athlete with impaired vision

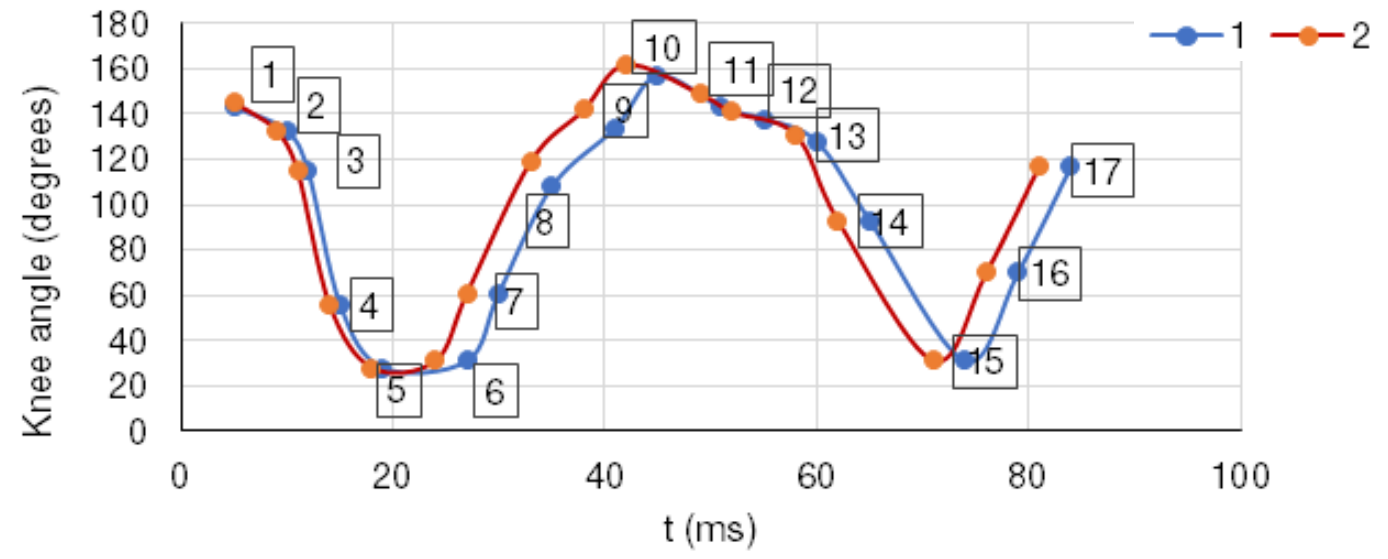

$\mathrm{t}(\mathrm{ms})$ - time from the beginning of the first analysed step, 1 - May-June $2015(n=36), 2$ - May-June $2016(n=36)$, squares include numbers of the analysed points

Figure 8 . Changes of the knee angle in the 100-m running of the elite athlete with impaired vision 
Table 2. Changes of results in running at short distances in the elite athlete with impaired vision as a result of applying the developed technique

\begin{tabular}{|c|c|c|c|c|c|c|c|c|}
\hline \multirow{2}{*}{ Distance $(m)$} & \multirow{2}{*}{ Testing period } & \multicolumn{7}{|c|}{ Statistical indicators } \\
\hline & & $n$ & $\bar{x}$ & $S D$ & $\mathrm{~m}$ & $\mathrm{t}$ & df & $p$ \\
\hline \multirow{2}{*}{60} & 1 & 14 & 7.20 & 0.17 & 0.04 & \multirow{2}{*}{1.24} & \multirow{2}{*}{27.00} & \multirow{2}{*}{0.22} \\
\hline & 2 & 15 & 7.10 & 0.23 & 0.06 & & & \\
\hline \multirow{2}{*}{80} & 1 & 20 & 9.82 & 0.23 & 0.05 & \multirow{2}{*}{1.75} & \multirow{2}{*}{36.00} & \multirow{2}{*}{0.09} \\
\hline & 2 & 18 & 9.60 & 0.51 & 0.12 & & & \\
\hline \multirow{2}{*}{100} & 1 & 12 & 12.46 & 0.36 & 0.10 & \multirow{2}{*}{2.43} & \multirow{2}{*}{22.00} & \multirow{2}{*}{0.02} \\
\hline & 2 & 12 & 12.06 & 0.45 & 0.13 & & & \\
\hline \multirow{2}{*}{120} & 1 & 7 & 14.62 & 0.41 & 0.16 & \multirow{2}{*}{1.16} & \multirow{2}{*}{12.00} & \multirow{2}{*}{0.27} \\
\hline & 2 & 7 & 14.38 & 0.35 & 0.13 & & & \\
\hline \multirow{2}{*}{150} & 1 & 16 & 19.24 & 0.87 & 0.22 & \multirow{2}{*}{0.21} & \multirow{2}{*}{31.00} & \multirow{2}{*}{0.84} \\
\hline & 2 & 17 & 19.15 & 1.37 & 0.33 & & & \\
\hline \multirow{2}{*}{200} & 1 & 17 & 26.45 & 1.53 & 0.37 & \multirow{2}{*}{0.08} & \multirow{2}{*}{36.00} & \multirow{2}{*}{0.94} \\
\hline & 2 & 21 & 26.41 & 2.03 & 0.44 & & & \\
\hline
\end{tabular}

1 - May-June 2015, 2 - May-June 2016, $n$ - number of measurements, df - degrees of freedom

different (Figures 6 and 7). In 2015, in some steps, there was a detention of a limb while moving it down, and in 2016, the detention disappeared (Figures 6 and 7, points 8-10).

A comparative analysis of running velocity curves of 2015 and 2016 showed that the proposed training program with emphasis on psychophysical aspects and improvement of kinaesthetic analyser performance improved the biomechanical characteristics of limb movement by eliminating delays during lowering the leg after hip raising. It seems that these biomechanical corrections were related with the application of exercises on unstable supports.

A tendency to improve the results at all distances and a significant increase in the results at a distance of $100 \mathrm{~m}$ were detected (Table 2).

It should be noted that in the training process of the surveyed athlete, the developed training program had a positive impact on the efficiency of running at short distances $(p<0.05$ at the distance of $100 \mathrm{~m}$, with a tendency of improvement at other distances). As a result, at the 2016 Paralympics, the athlete achieved results that exceeded the trend related to the regression models of polynomial functions, and became the champion of the world and the silver medallist, with the result of $11.71 \mathrm{~s}$ at $100-\mathrm{m}$ running.

\section{Discussion}

As a result of the conducted studies, the hypothesis of the effectiveness of applying an individually oriented training program based on the features of neurodynamic functions and biomechanical characteristics of running was confirmed. The study showed the feasibility and effectiveness of using the method of individualization, taking into account the neurodynamic features in the training of elite athletes with impaired vision. The project was based on the data that we received in previous studies, where it was found that the most pronounced neurodynamic function of the examined athlete was the strength of the nervous system. This causes some discrepancy with the literature which describes the complex of indicators of sprinters' nervous system, pointing at the re-
Literature data emphasize that the strength of the nervous system is more characteristic of endurance sports.

Our studies [15] revealed that besides the neurodynamic characteristics typical of sprinters (speed of simple reactions and mobility of the nervous system), the athlete under study exhibited a pronounced capacity, i.e. strength, of the nervous system. The strength of the nervous processes is an individual feature of the examined athlete. The development of the strengths gives additional information to the central nervous system about the athlete's movement [16], thereby blocking the danger signal due to visual analyser failure, and the athlete's running speed does not decrease. Thus, a strong nervous system helps the elite athlete with impaired vision to present high athletic performance in sprint.

The obtained data complement the results of the research by Lyzohub et al. [3], Korobeynikov et al. [4], and Ilin [8, 9] on the presence of neurodynamic features in representatives of different sports. Kozina et al. [5] shows the influence of the neurodynamic parameters characterizing the performance (force) of the nervous system on the results in short distance running. Also, theoretical provisions have been formulated on the mechanisms of limiting the speed of running in athletes with visual impairments and on possible ways to compensate for the restricted opportunities in sprinting [6].

The data that we obtained previously $[15,16]$ testify to the ability of the examined athlete to prolong the work of the nervous system, and therefore to the strength of her nervous system. This may be due to its individual characteristics, as well as the development of compensatory mechanisms associated with the failure of the visual analyser. The surveyed athlete is also characterized by a high ability to develop speed at a distance. This requires the performance of the nervous system, which is reflected in the high significance of the neurodynamic parameters in the quality data. The high performance of the nervous system observed in the examined female athlete may also be a compensatory mechanism of visual impairment. Thus, one can conclude that in athletes with impaired vision, there is an increased influence of neurodynamic factors as compensatory mechanisms. 
The training program for the 2016 Paralympics for the elite athlete with impaired vision was based on the data obtained in previous studies. In addition, the program included kinaesthetic analyser development exercises using unstable platforms. Nowadays, in many spheres of fitness and in the training process of athletes, the use of tools aimed at training the so-called 'core muscles' is becoming more widespread [20-22]. Willson et al. [23] describe 'core' as a lumbar-pelvic complex that includes the lumbar spine, pelvis, and hip joints, as well as active and passive tissues which produce or support the movements of this segment. Anderson and Behm [22] believe that weight training not only increases muscle strength, but also can improve the coordination of muscle activity in synergists and antagonists, increasing stability. Repeated application of an unstable surface allows to recognize changes in the surface as a result of the coordination of proactive [24] or positive feedbacks [25]. Stabilization exercises and balance training can significantly improve neuromuscular control [26]. Moreover, the sensitivity of conducting afferent pathways increases with equilibrium training and motor skills $[27,28]$, which leads to a decrease in the reaction time of stabilizing muscles [29]. Thus, the use of weight training and balance training in rehabilitation programs can increase the activation of core muscles and improve coordination or motor control over core stabilizers. The use of destabilizing devices in training improves proprioception and increases the 'sensory efficiency' of soft tissues that stabilize the knee and ankle joints [24, 25, 29].

Proprioceptive training includes a set of exercises performed in instability that help to strengthen the proprioceptive signals coming from the peripheral parts of the body, especially from the extremities [20, 21, 23]. Proprioceptive training can significantly improve the body sensory-motor function, i.e. the ability to sense and respond to changes occurring within the body. Training with balance or postural stabilization develops the nervous system, activates the joint work of different parts of the body, and increases the reactivity and coordination of the body [24-26].

Applying the developed recommendations helped the examined athlete to become the silver medallist of the 2016 Paralympic Games in track and field.

It should also be noted that the changes in the speed of movement of the ankle and knee joints became somewhat different (Figures 6 and 7). In 2015, in some steps, the limb was detained during its downward movement, and in 2016 , the delay disappeared (Figures 6 and 7, points 8-10). In the initial analysis of the biomechanics of motion for the athlete's 100-m running, these delays were explained by a difficulty in regulating the speed of running owing to the lack of information from the visual analyser. That is, the body seems to be 'insured' in this way from loss of direction, falling, etc. But this leads to a decrease in running speed, and visually looks as if some 'entrenched' the athlete when running. We noticed some reserve in the athlete to increase her running speed if this effect were eliminated. The developed training program was aimed at accentuating the strengths of the athlete; among others, her strong nervous system was highlighted as it allows to maintain maximum speed at a distance for a long time. It was suggested that, by avoiding delays in lowering the leg, which were encountered in some running steps, it was possible to increase the speed of running at a distance, improving the leading quality of the athlete.

A comparative analysis of running velocity curves of 2015 and 2016 showed that the proposed training program with an emphasis on psychophysical aspects and improvement of kinaesthetic analyser performance allowed to improve the biomechanical characteristics of limb movement by eliminating delays during lowering the leg after hip raising. It seems that these biomechanical corrections were related with the application of exercises on unstable supports.

As the use of exercises on unstable supports was coupled with the development of speed endurance, the impact of this type of training was heightened. In addition, the entire program of training was designed in such a way that the emphasis was on the development of speed at a distance by improving the regulation of movement by the central nervous system and improving the operation of the kinaesthetic analyser. Better kinaesthetic regulation of movements during running allowed to enhance the compensatory function of the kinaesthetic analyser in the athlete with the lack of visual analyser. One can conclude that this was reflected in overcoming the subconscious fear of disrupting the direction of movement or getting an injury, which had led to a delay in speed when lowering the foot on the track.

As a result, in May-June 2016, this delay and 'entrapment' when running disappeared, which resulted in a significant increase in speed and acceleration not only when lifting, but also when lowering the foot on the track. This, in turn, reduced the time of the running steps.

In addition, the ability to relax, which is enhanced by the application of unstable supports, especially when performing simulated jogging movements, also helps avoid unnecessary stress during running, and thus improves the conditions for the recovery of creatine phosphate in the muscles. This led to better movement coordination and higher speed of running steps at a distance.

Further research is required to verify these provisions in other visually impaired sprinters.

\section{Recommendations}

When developing individual training programs for athletes with visual impairment, one has to consider the biomechanical features of the running technique. An emphasis should also be placed on leading factors in the individual structure of the athletes' readiness, a tendency to a certain style of motor activity. Unstable platforms are recommended to improve motor control and running techniques.

\section{Limitations}

The obtained results are applicable only to sprinters with visual impairment. Additional research is needed for representatives of other sports, as well as for Olympic athletes.

\section{Conclusions}

1. A program of individual preparation of an elite athlete with impaired vision for the 2016 Paralympics was developed and substantiated. The program was based on the accelerated development of speed endurance and kinaesthetic analyser.

2. The developed methodology had a positive effect on the biomechanical indicators of running. As a result of training under the developed program, changes were observed in the values of the following parameters: angle in the knee joint at the time of thigh raising (from $108 \pm 2.210$ to $119 \pm 1.250$ degrees, $p<0.05)$, speed of movement of the ankle and knee joints at the moments of thigh raising (ankle joint: from $9.68 \pm 0.78 \mathrm{~m} \cdot \mathrm{s}^{-1}$ to $10.06 \pm 0.76 \mathrm{~m} \cdot \mathrm{s}^{-1}, p<0.05$; knee joint: from $3.80 \pm 0.06 \mathrm{~m} \cdot \mathrm{s}^{-1}$ to $\left.4.99 \pm 0.25 \mathrm{~m} \cdot \mathrm{s}^{-1}, p<0.01\right)$ and at the time of lowering the leg (ankle joint: from $4.7 \pm$ 
$0.67 \mathrm{~m} \cdot \mathrm{s}^{-1}$ to $10.82 \pm 0.58 \mathrm{~m} \cdot \mathrm{s}^{-1}, p<0.001$; knee joint: from $1.77 \pm 0.11 \mathrm{~m} \cdot \mathrm{s}^{-1}$ to $\left.8.19 \pm 0.08 \mathrm{~m} \cdot \mathrm{s}^{-1}, p<0.001\right)$.

3. A significant increase in the acceleration of ankle and knee joints was revealed at the time of thigh raising and at the time of lowering the leg $(p<0.05 ; p<0.001)$. The strength that the lower limb developed during the running steps also increased significantly $(p<0.001)$. A significant decrease was observed in running time of the running steps during the development of maximum speed at a distance $(p<0.05)$. A delay was noted during leg lowering after thigh raising. The running time at the distance of $100 \mathrm{~m}$ significantly improved (from $12.46 \pm 0.36 \mathrm{~s}$ to $12.06 \pm 0.45 \mathrm{~s}, p<0.05$ ). As a result, at the 2016 Paralympics, the athlete became the world champion and silver medallist, with the result of $11.71 \mathrm{~s}$ at the 100-m race.

\section{Acknowledgements}

The study was conducted in accordance with the research work of Ministry of Education and Science of Ukraine for 2019-2020 'Theoretical and methodological foundations of technique development for the restoration of musculoskeletal system and functional state and prevention of injuries in representatives of different age groups in physical culture and sports' (No. 0119U100634).

\section{Disclosure statement}

No author has any financial interest or received any financial benefit from this research.

\section{Conflict of interest}

The authors state no conflict of interest.

\section{References}

1. Znazen H, Slimani M, Miarka B, Butovskaya M, Siala H, Messaoud T, et al. Mental skills comparison between elite sprint and endurance track and field runners according to their genetic polymorphism: a pilot study. J Sports Med Phys Fitness. 2017;57(9):1217-1226; doi: 10.23736/ S0022-4707.16.06441-0.

2. Kozina Z, Shepelenko T, Osiptsov A, Kostiukevych V, Repko O, Bazilyuk T, et al. Factor structure of the integral readiness of aerobics athletes (women). J Phys Educ Sport. 2017;17(Suppl. 5):2188-2196; doi: 10.7752/jpes. 2017.s5227.

3. Lyzohub V, Nechyporenko L, Pustovalov V, Suprunovych $V$. Specialized training and bioenergy state of football players with different typological properties of the higher parts of the nervous system. Science and Education. 2016;8:107-112; doi: 10.24195/2414-4665-20168-21.

4. Korobeynikov G, Mazmanian K, Korobeynikova L, Jagiełło W. Psychophysiological states and motivation in elite judokas. Arch Budo. 2010;6(3):129-136.

5. Kozina Z, Chebanu O, Repko O, Kozin S, Osiptsov A. Influence of typological features of the nervous system on individual performance in running for short distances in athletes with visual impairment on the example of an elite athlete. Phys Activ Rev. 2018;6:266-278; doi: 10.16926/par.2018.06.31.

6. Kozina ZL, Chebanu OI, Prokopenko IF, Korobeynikov GV, Korobeynikova LG, Korobeinik VA, et al. The implementation of the concept of individualization in training elite female athletes with visual impairment in the sprint. J Phys Educ Sport. 2018;18(1):282-292; doi:
7. Blecharz J, Siekańska M. Temperament structure and ways of coping with stress among professional soccer and basketball players. Biol Sport. 2007;24(2):143-156.

8. Ilin EP. Differential psychophysiology, its place and role in the study of the personality of athletes [in Russian]. Sportivnaya i Vozrastnaya Psihofiziologiya. 1974;(0)1:5-24.

9. Ilin EP. The strength of the nervous system and the methods of its investigation [in Russian]. Psihofiziologicheskie Osnovyi Fizicheskogo Vospitaniya i Sporta. 1972;(0)1:5-12.

10. Chen Y, Zhou A-Q, Qian G-R, Gong X-Q. Pre-competition psychological training of middle school athletes in middle and long distance race from the perspective of temperament type-case study. In: Ma XD, Xu F (ed.), Proceedings of the Xi'an 2012 International Conference of Sport Science \& Physical Education, vol. 2: Physical education and innovation. Liverpool: World Academic Union (World Academic Press); 2012; 177-181.

11. Brazil A, Exell T, Wilson C, Willwacher S, Bezodis I, Irwin G. Lower limb joint kinetics in the starting blocks and first stance in athletic sprinting. J Sports Sci. 2017; 35(16):1629-1635; doi: 10.1080/02640414.2016.1227465.

12. Anderson K, Behm DG. Trunk muscle activity increases with unstable squat movements. Can J Appl Physiol. 2005;30(1):33-45; doi: 10.1139/h05-103.

13. Behm DG, Anderson KG. The role of instability with resistance training. J Strength Cond Res. 2006;20(3):716722; doi: 10.1519/R-18475.1.

14. Fagher K, Forsberg A, Jacobsson J, Timpka T, Dahlström Ö, Lexell J. Paralympic athletes' perceptions of their experiences of sports-related injuries, risk factors and preventive possibilities. Eur J Sport Sci. 2016;16(8): 1240-1249; doi: 10.1080/17461391.2016.1192689.

15. Kozina ZL, Chayka OI. Interconnection of psycho-physiological indicators and performance in running at $100 \mathrm{~m}$ at athletes of high qualification with visual impairment (for example an elite athlete) [in Russian]. Health Sport Rehabilitation. 2018;4(2):73-86; doi: 10.5281/zenodo. 1342472.

16. Chaika OI. The role of psychophysiological indicators in the effectiveness of qualified sprinters with visual impairment (the example of an elite athlete) [in Russian]. Health Sport Rehabilitation. 2018;4(3):62-74.

17. Safronov D, Chaika O, Belozerov I, Kozin S, Kozina Z. Neurodynamic compensatory mechanisms of visual impairment and biomechanical indicators of running in an elite athlete in the Paralympic sprint [in Russian]. Journal of V.N. Karazin Kharkiv National University. 2019;37:6282; doi: 10.26565/2313-6693-2019-37-08.

18. Kozin SV. Biomechanical substantiation of the technique of hanging in rock climbing [in Russian]. Health Sport Rehabilitation. 2019;5(1):25-35; doi: 10.34142/HSR.2019. 05.01.03.

19. Kozina Z, lermakov S, Bartík P, Yermakova T, Michal J. Influence of self-regulation psychological and physical means on aged people's functional state. J Hum Sport Exerc.2018;13(1):99-115; doi:10.14198/jhse.2018.131.10.

20. Behm DG, Drinkwater EJ, Willardson JM, Cowley PM. The use of instability to train the core musculature. Appl Physiol Nutr Metab. 2010;35(1):91-108; doi: 10.1139/ H09-127.

21. Behm DG, Leonard AM, Young WB, Bonsey WA, MacKinnon SN. Trunk muscle electromyographic activity with unstable and unilateral exercises. J Strength Cond Res. 2005;19(1):193-201; doi: 10.1519/1533-4287(2005)19 $<$ 193:TMEAWU>2.0.CO;2. 
22. Anderson K, Behm DG. The impact of instability resistance training on balance and stability. Sports Med. 2005; 35(1):43-53; doi: 10.2165/00007256-200535010-00004.

23. Willson JD, Dougherty CP, Ireland ML, Davis IM. Core stability and its relationship to lower extremity function and injury. J Am Acad Orthop Surg. 2005;13(5):316-325; doi: 10.5435/00124635-200509000-00005.

24. Pavol MJ, Pai Y-C. Feedforward adaptations are used to compensate for a potential loss of balance. Exp Brain Res. 2002;145:528-538; doi: 10.1007/s00221-002-1143-4.

25. Cosio-Lima LM, Reynolds KL, Winter C, Paolone V, Jones MT. Effects of physioball and conventional floor exercises on early phase adaptations in back and abdominal core stability and balance in women. J Strength Cond Res. 2003;17(4):721-725; doi: 10.1519/15334287(2003)017<0721:eopacf>2.0.co;2.

26. Carter JM, Beam WC, McMahan SG, Barr ML, Brown LE. The effects of stability ball training on spinal stability in sedentary individuals. J Strength Cond Res. 2006;20(2): 429-435; doi: 10.1519/R-18125.1.

27. Caraffa A, Cerulli G, Projetti M, Aisa G, Rizzo A. Prevention of anterior cruciate ligament injuries in soccer. A prospective controlled study of proprioceptive training. Knee Surg Sports Traumatol Arthrosc. 1996;4(1):19-21; doi: 10.1007/BF01565992.

28. Borghuis J, Hof AL, Lemmink KA. The importance of sensory-motor control in providing core stability: implications for measurement and training. Sports Med. 2008;38(11):893-916; doi: 10.2165/00007256-200838 110-00002.

29. Vera-Garcia FJ, Elvira JL, Brown SH, McGill SM. Effects of abdominal stabilization maneuvers on the control of spine motion and stability against sudden trunk perturbations. J Electromyogr Kinesiol. 2007;17(5):556-567; doi: 10.1016/j.jelekin.2006.07.004. 